\title{
WAVE-INDUCED LIQUEFACTION OF MARINE ON LATEST PROGRESS
}

\author{
Dr. A. Gayathiri \\ Asst.Professor, Petroleum Engineering, AMET University, India

\section{Dr. A. Balasubramanian} \\ Asst. Professor, Petroleum Engineering, AMET University, India
}

\begin{abstract}
Because of cyclic stacking of water waves, the seabed soil may experience a procedure called liquefaction where pore weight balances compelling burdens in the dirt and debilitates the heap bearing limit prompting destroying outcomes for seaside and seaward structures. This marvel has attracted much consideration the most recent four decades. Particularly inside of the late years, by distinctive scientists including the creators of this paper, vital progressions have been made toward comprehension the material science connected with liquefaction as well as making quantitative appraisals of wave-impelled liquefaction hazard and its outcomes on such structures. The destinations of this paper are two folds: (1) To present a brief survey of those most exceptional methodologies and systems, (2) To indicate out a few of the handy issues so far to be tackled.
\end{abstract}

Key words: Seaward, Water Waves

Cite this Article: Dr. A. Gayathiri and Dr. A. Balasubramanian, Wave-Induced Liquefaction of Marine on Latest Progress. International Journal of Design and Manufacturing Technology 6(2), 2015, pp. 42-47. https://iaeme.com/Home/issue/IJDMT?Volume $=6 \&$ Issue $=2$

\section{INTRODUCTION}

Wave-incited liquefaction of seabed, a wonder with disastrous outcomes, has been broadly concentrated on over the previous decades through expository, numerical and trial implies. Despite the fact that there have been a few studies directed to comprehend the dynamic reaction and precariousness of seabed under waves, there are generally constrained measure of studies led up to this point to comprehend the dirt disappointments connected with establishments lying inside or on the seabed. Yet, it has not been plainly characterized what measures or moves to make to keep these disappointments nor do any national or global configuration manuals exist distinguishing these measures expressly. 
Besides, the requirement for fitting configuration of marine structures is relied upon to develop quickly later on because of the environmental change which expands the greatness and recurrence of solid tempests watched all around. From this sense, a standout amongst the most imperative dangers to the marine foundation turns out to be the precariousness of seabed and seabed-structure framework under wave-incited cyclic and effect loads. The geotechnical perspectives as well as seaside and marine hydrodynamics assume a noteworthy part in the start of these dangers.

Be that as it may, there still remains a huge requirement for further studies to comprehend the hidden mechanics, figure models, and create devices for the reaction and shakiness of some imperative seabed-structure frameworks. In this paper, the improvements made as of late to fulfill this need are quickly condensed. Creators plan to exhibit the results of the latest examination on the point that they have been included, and additionally other key studies directed before theirs and contemporarily. The paper basically concentrates on two parts of wave-actuated liquefaction considers: (1) momentary liquefaction and (2) lingering liquefaction.

\section{MECHANISM OF LIQUEFACTION}

Liquefaction is the procedure where the overburden anxiety of the dirt is adjusted by the pore weight and, thus, soil acts like a fluid blend of grains and water. Such a dirt would have no bearing limit and dependability of structures laying on/in it would have a danger of disappointment. Waves and additionally seismic tremors can bring about the liquefaction of marine soils. The recent is out of the present's extent study. There are two noteworthy systems of wave-impelled liquefaction: the oscillatory component (passing/immediate liquefaction) and the lingering instrument (leftover/dynamic liquefaction).

The previous is driven by the oscillatory segment of pore weight and happens for the most part close to the seabed surface where the pore water may contain little measure of gas in the voids while the recent is brought about by the development of pore weight because of wave-incited irreversible cyclic shear mishapenings. The late improvements on prompt liquefaction are for the most part accomplished by diagnostic and numerical strategies though lab physical models bolstered by explanatory results are generally used to ponder the leftover liquefaction and its outcomes.

\subsection{Instantaneous Liquefaction}

This is conceivable notwithstanding when the dirt solids are considered to stay straight isotropic versatile. At the point when a wave trough is disregarding the seabed it will create a negative weight in abundance of hydrostatic weight. On the off chance that there is gas content (i.e. air rises) in the middle of the dirt grains, the weight will rapidly be dispersed by the voids and an upward coordinated weight slope (drainage stream) will be produced.

The wave-incited liquefaction happens when the submerged weight of soil skeleton is not exactly the upward drainage power applied on it. This standard was further stretched out for a more broad anxiety state by Tsai (1995).

\section{Residual Liquefaction}

Under dynamic wave activity, seabed soil experiences cyclic shear distortions which revamp the dirt grains to the detriment of pore volume. As the pore volume lessens, the pore-water is pressurized and constrained out of the inter granular space, prompting pore-weight development. In the event that the developed weight is not scattered 
sufficiently quick, the pore-water weight may achieve levels surpassing the introductory mean ordinary successful anxiety. Thus, soil skeleton vanishes and soil acts like a fluid prompting the liquefaction state.

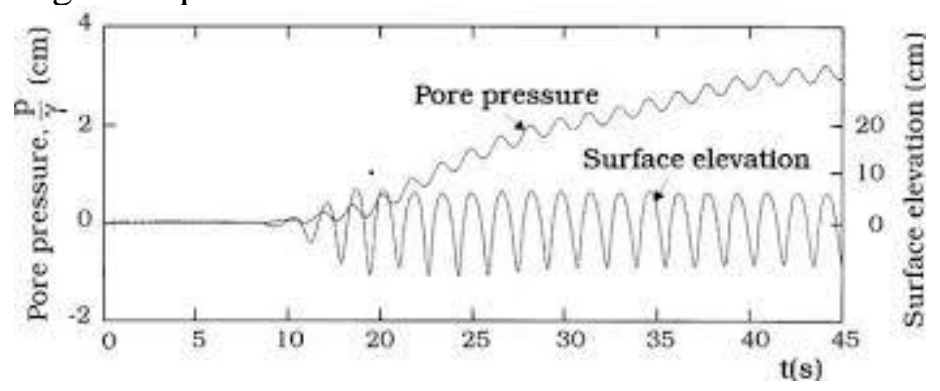

Figure 1 Pour water pressure

\section{STATE-OF-THE-ART}

\subsection{Earlier Studies}

In the most recent decades, advancement has been made towards understanding the dangers, liquefaction specifically, under wave activity. Rahman et al. (1977) broke down the wave-actuated pore weights under a gravity structure with a decoupled investigation. Mynett and Mei (1982) built up an answer for the wave-affected hassles in immersed seabed under a caisson. Reaction of fundamental seabed has later been viewed as (Mase et al., 1994).

Shakiness because of liquefaction in seabed has been one of the huge reasons for disappointment of such structures. Sakakiyama et al. (1991) built up a permeable body model to study surface removals in and close to a composite sea wall. Later, these were considered with changing degrees of exactness (Oumeraci and Partensky, 1990; Losada et al. 2008).

Wave-incited pore weight development and came about liquefaction has additionally been concentrated tentatively. Sumer et al's. (1999) study was one of the pioneer works of wave flume liquefaction tests. They focused on remaining liquefaction of seabed and coasting/sinking of pipelines in the melted seabed. Later, the succession of procedures in the marine seabed that prompts remaining liquefaction was exhibited in point of interest by some benchmark wave flume tests (Sumer et al., 2006). Sumer and Fredsoe (2002) added to a down to earth strategy to evaluate the pore weight development and liquefaction capability of marine seabed, taking into account the arrangement of Hsu and Jeng (1994).

\subsection{Recent Studies}

In the most recent five years, the wave-incited liquefaction of seabed under dynamic, standing and breaking waves have been concentrated on through different means broadly by analysts including the creators of this paper. These late studies are exhibited beneath in this segment.

\subsubsection{Analytical and Numerical Studies on Wave-Induced Instantaneous Liquefaction}

The wave-prompted quick liquefaction, considering a solitary soil layer in the space, was as of late examined by Ulker et al. (2010, 2012). Ulker et al. (2009) displayed an 
arrangement of summed up logical answers for reaction of a soaked permeable seabed under plane strain condition incorporating every one of the inertias in the comparisons.

For average estimations of wave period and seabed porousness, the locales of appropriateness of the three details are distinguished and plotted in parametric spaces. Ulker et al. (2010) examined the standing wave-prompted dynamic reaction and unsteadiness of seabed around a caisson embankment. A seabed-rubble-caisson jetty framework is demonstrated utilizing limited components.

Liquefaction profundities in the rubble and the seabed are additionally assessed. Completely alert (FD) examination yielded bigger ranges of liquefaction along the seabed contrasted with semi static (QS) structure. As the porousness of seabed builds, condensed zones diminish in size. Seabed with bigger level of immersion lessens the condensed territories, which achieves a no liquefaction state for completely soaked case. Ulker et al. (2012) considered the breaking wave-incited liquefaction around a caisson sea wall. Breaking waves were found to bring about liquefaction in the framework.

The shakiness of the permeable soil due to wave stacking is explored as far as prompt liquefaction. Limited component numerical results are confirmed with their explanatory partners, which are additionally grown in that. At that point, the issue of a two-layer soil under waves both in an open area and before a vertical divider is considered as far as reaction varieties and quick liquefaction. The outcomes show that the two-layer reaction is fundamentally not the same as that of an ordinary single-layer methodology. In this study, interestingly a completely dynamic expository arrangement has been inferred for multi-layer circumstance and its liquefaction conduct has been explored.

\section{2.2 Experimental and Analytical Studies on Wave-Induced Residual Liquefaction}

As specified above, there are just a couple of functional and settled systems for estimation of remaining liquefaction potential. One of them, the strategy proposed by Sumer and Fredsoe (2002) has as of late been approved against a wave flume dataset by Sumer et al. (2012) where a numerical case and comments on down to earth application were incorporated in the matter of how the system can be executed by a planner.

Here liquefaction understanding waves has critical contrasts contrasted with dynamic wave case alongside a few similitudes. It is demonstrated that pore weight development begins underneath the nodal segment first and afterward the procedure spreads towards antinodes by a dispersion system controlled by the coefficient of solidification of the dirt. All things considered, number of waves bringing about liquefaction at the hubs equivalents to that for dynamic waves for the same wave tallness.

Henceforth, the liquefaction potential appraisal strategy for dynamic waves can likewise be utilized for standing waves as a first estimation, gave that the tallness of the superposed wave is taken as the agent wave stature (Kirca et al., 2013). In marine building, it is very prone to experience clayey seabed. There had been distinctive perspectives among the scientists with respect to the impact of earth substance on liquefaction, especially for wave-prompted case. Some had proposed that clayey soil was liquefaction safe while others contended the inverse.

To illuminate this point, Kirca et al. (2012b, 2014) performed wave flume tests where impact of earth substance on wave actuated liquefaction was observed. They 
tried immaculate sediment and unadulterated sand versus distinctive rates of residue mud and sand-dirt blends.

Past this breaking point, notwithstanding, the liquefaction resistance expanded significantly, an inverse conduct. The previously stated breaking point was apparently mud particular (saw to be approximately $30 \%$ for that specific case). As per Kirca et al. (2014): (1) for moderately little rate of mud, the dirt's penetrability is diminished which assisted the pore weight development and continuously liquefaction (porousness commanded conduct). (2) When the earth sum is raised over an utmost, the mud lattice typifies the grains such that no significant shear strain can happen (versatility commanded conduct). For clayey sediment or sand, standard liquefaction potential appraisal systems can be utilized given that the dirt parameters are characterized legitimately.

\section{CONCLUSION}

In this paper, the late advancements of wave-affected liquefaction, especially the studies in which the present creators are included, are exhibited. Particularly in the most recent five years, scientific systems were produced to assess the seabed reaction to wave stacking and prompt liquefaction potential.

These strategies were stretched out to multi-layer and to $2 \mathrm{D}$ completely element case. Additionally, numerical techniques were used to evaluate the reaction of marine structure establishments to breaking and non-breaking waves. Then again, trial offices have been successfully used to portray the leftover liquefaction under dynamic/standing waves, to accept semi-systematic instruments for remaining liquefaction and to discover responses to pragmatic issues connected with lingering liquefaction, for example, the sinking harm of structures in condensed soil and impact of mud substance on liquefaction potential. Despite the fact that there have been upgrades in this field, there are as yet remaining issues and unanswered inquiries yet to be managed. There is still a requirement for a non specific and accepted poro-elastoplastic soil display that records for the dynamic seabed reaction and insecurity

\section{REFERENCES}

[1] Lara, J.L., Losada, I. J. and Guanche, R., (2008). Wave interaction with lowmound breakwaters using a RANS model. Ocean Engineering. Vol. 35(13), pp. 1388-1400.

[2] Losada, I. J., Lara, J.L., Guanche, R., Gonzalez Ondima, J.M., (2008). Numerical analysis of wave-overtopping of rubble-mound breakwaters. Coastal Engineering. Vol. 55(1), pp. 47-62.

[3] Maeno, S. and Nago, H., (1988). Settlement of a concrete block into a sand bed under wave pressure variation. in Kolkman et al. (Eds.), "Modelling Soil-Water-Structure Interactions", pp. 67-76.

[4] Mase, H., Sakai, T., Sakamoto, M., (1994). Wave-induced pore water pressures and effective stresses around breakwater. Ocean Engineering. Vol. 21(4), pp.361-379.

[5] Mynett, A. E. and Mei, C. C., (1982). Wave-induced stresses in a saturated poroelastic seabed beneath a rectangular caisson. Geotechnique. Vol. 32(3), pp. 235-247. 
[6] Oumeraci, H. and Partensky, H.W., (1990). Wave induced pore pressures in rubble mound breakwaters. Proc. of the 22th International Conference on Coastal Engineering, July 2-6, pp. 1334-1347, Delft, Netherlands.

[7] Hsu, J. R. C., and Jeng, D. S. (1994). Wave-induced soil responses in an unsaturated anisotropic seabed of finite thickness. Int. J. Numer. Anal. Methods Geomech., 18(11), 785-807.

[8] Jeng, D. S., Cha, D. H., Lin, Y. S. and Hu, P. S., (2001). Wave-induced pore pressure around a composite breakwater. Ocean Engineering. Vol. 28(10), pp.1413-1435.

[9] Kudella, M., Oumeraci, H., De Groot, M. B. and Meijers, P., (2006). Largescale experiments on pore pressure generation underneath a caisson breakwater. J. Waterway, Port, Coas, Ocean, Eng. ASCE, 132(4), 310-324.

[10] Kirca, V.S.O., Sumer, B.M., Fredsøe, J., (2012a). Residual liquefaction under standing waves. Proc. of 22nd ISOPE Conference, Rhodes, Greece, June 17-22, 2012. 